Dept. of Zoology

Fac. of Science, Assiut Univ, Assiut, A.R.E.

Head of Dept. S.H. Esmail

\title{
EXPERIMENTS ON EFFECT OF ALTOSID (GROWTH REGULATOR) ON SOME DEVELOPMENTAL STAGES OF CULEX UNIVITTATUS THEOBALD. (DIPTERA: CULICIDAE) \\ (With 4 Tables)
}

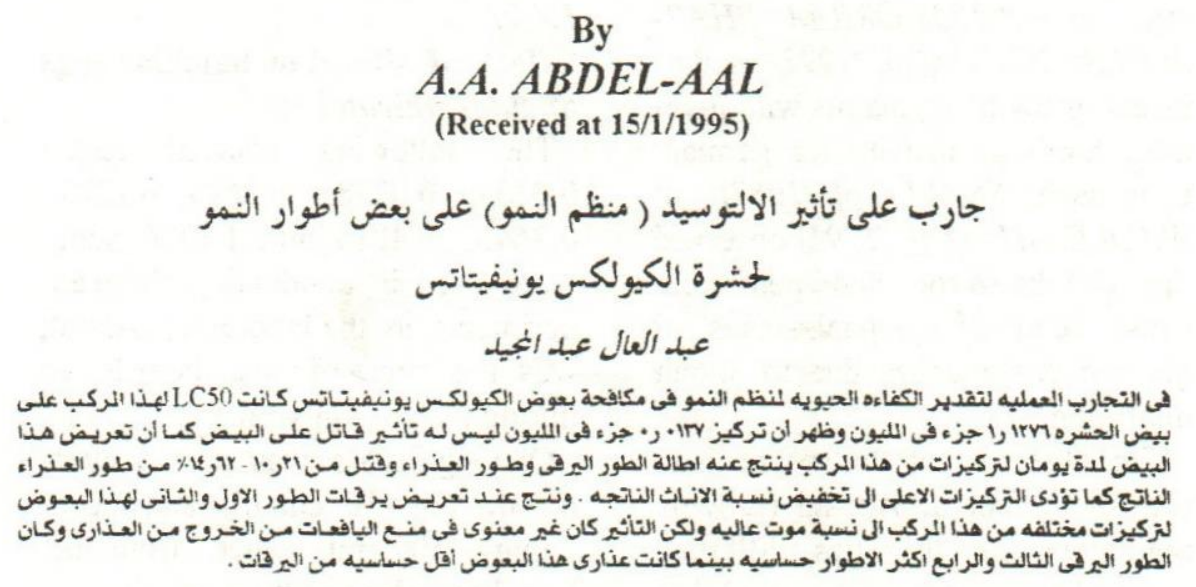

\section{SUMMARY}

The LC50 of Altosid against Culex univittatus eggs was $1.1276 \mathrm{ppm}$. The compound at $0.0137 \mathrm{ppm}$ had no ovicidal activity. Exposure of Culex univittatus eggs for 2 days resulted in prolongation of larval and pupal period; $10.21-14.62 \%$ mortality in resulting pupae and reduced female ratio at higher concentrations. Exposure of first and second instar larvae of $C$ ulex univittatus to different concentrations resulted in larval mortality, but the effect on inhibition of adult emergence was not significant. The third and fourth instar larvae were the most sensitive whereas pupae were less sensitive to Altosid.

Keywords: Culex univittatus, Theobald and Altosid (growth regulator)

\section{INTRODUCTION}

Altosid (insect growth regulator) was found to affect larvae and pupae of many species of insects in different countries. CUMMING and
MOKAGUE (1973) found that Altosid inhibited adult emergence of Simulium decorum; PREE (1974), studied the effective of insect developmental inhibitors against both lar- 
vae and pupae of the apple maggot, RHAGOLETIS POMONELLA; RETENAKARAN, (1973, 197t) induced ovarian development and resorption of fat bodies and induction of sexual maturity in the white pine weevil, Pissodes strobi by some analogues of juvenile hormone; $E D W A R D S$ (1975), observed the juvenile hormone analogue caused broad death and prevented egg laying in MONOMORIUM PHARAONIS; REID et lal. (1992) used of insect growth regulators with juvenile hormone activity for german cockroach; SHAFI et al. (1987) and WADLEIGH et al. (1991) observed the diffubenzuron and penfluron cause death of nymphal stages of german cockroaches due to moult inhibition.

The objective of this paper is to test the effect of Altosid (growth regulator) on the eggs, different stage larvae and pupae of Culex univittatus.

\section{MATERIAL AND METHODS}

Two formulations of Altosid (emulsion and granules) were kindly provided by Zoecon corporation 975 california to be tested against culicine mosquitoes. It is a Juvenile hormone analogues which is known to regulate insect growth.

As far as it chemical and physical properties, Altosid is isopropy 11methoxy-3, 7, 11 trimethyl dodeca 2,4 dienoate, Patent pending, C19 $\mathrm{H} 34 \mathrm{O} 3$. It is colourless liquid with molecular weight 310 , specific gravity $0.8856 \mathrm{gm} . / \mathrm{c} . \mathrm{c}$ at $20^{\circ} \mathrm{C}$ and vapour pressure $2.37 \times 19^{-5} \mathrm{~m} \mathrm{Hg}$ at $25^{\circ} \mathrm{C}$ and $1.60 \times 10^{-4} \mathrm{~mm} \mathrm{Hg}$ at $40{ }^{\circ} \mathrm{C}$. Altosid is soluble in nonaqueous organic solvents and its water solubility is $1.39 \mathrm{ppm}$. Lc 50 to rats is greater than 50.000 $\mathrm{mg} / \mathrm{kg}$., greater than $80 \mathrm{ppm}$ for blue gills and greater than $4.4 \mathrm{ppm}$ for tront. Dermal and eye irritation is minimal to rabbits (ANONYMOUS, 1972).

Effect of Altosid on hatching eggs of culex univittatus

The following concentrations $0.0137,0.0238,0.0495,0.1273$, $0.2645,0.4814$ and $1.1276 \mathrm{ppm}$, were used in conducting these experiments in the laboratory (Assiut, was the soure of mosquitoes tested during the present work).

One egg mass was put in every plastic pot (10 cm diameter) containing $100 \mathrm{ml}$ water from the breeding place of the mosquitoes in the laboratory. After hatching the number of larvae were counted in every concentration and in the control, 3 replicates were used for each treatment.

Effect of Altosid on diferent larval instar of Culex univittatus

Sufficient larvae in their early first, second, third and instar were obtained from labporatory breed. 50 selected larvae of every instar were transferred to a plastic pot $(10 \mathrm{~cm}$. diameter) which contained $100 \mathrm{ml}$ of tap water and $1 \mathrm{ml}$ of appropriate concentration of Altosid. The control pots were prepared as described 


\section{ALTOSID, DEVELOPMENTAL STAGES OF CULEX}

above without using Altosid. Three replicates were prepared for each treatment. After an exposure period of $48 \mathrm{hrs}$, larvae were transferred to a plastic pots filled with tap water and fed on yeast and fine bread until pupation. Pupae were transferred to cages till adult emergence. Dead larvae and pupae were recorded. The tests were performed under water temperature of $20-30^{\circ} \mathrm{C}$.

The same technique was conducted on the pupae of Culex univittatus.

\section{RESULTS}

Are presented in Tables 1 - 4 .

\section{DISCUSSION}

Data (Table I) represent the ovicidal effect of Altosid on Culex univittatius eggs (0-24 hrs age). No ovicidal activity was found at concentration of $0.0137 \mathrm{ppm}$. The grandal increase of Altosid concentration was accompanied by gradual decrease in hatching rate. The Lc50 (The concentration which inhibits $50 \%$ of egg hatching) was found $1.1276 \mathrm{ppm}$.

Larvae which succeeded to hatch in the previous treatments were reared in the laboratory to study the latent effect of Altosid on larval mortality, larval periods, pupal perriod, pupal mortality and sex ratio (Table 2).

Data reveal that exposure of Culex univittatus eggs for 2 days to the concentrations tested caused 8$20 \%$ mortality of the larvae. Altosid was found to prolong larval and pupal periods. The period of the former stage was 8.5 days with Altosid concentration of $0.1273 \mathrm{ppm}$. compared with 7.92 days in the control. The period of the latter stage was 3.58 days at concentration of 0.1273 ppm compared with 2.81 days in the control.

Besides, this compound caused $10.21-14.62 \%$ mortality of the resulting pupae. The effect seems to extend to the female ratio was it was observed that, at concentration of $0.1273 \mathrm{ppm}$. female ratio as $76.83 \%$, gradual increase of concentration was accompanied by gradual decrease in female ratio (at concentration $1.1276 \mathrm{pmm}$ female ratio was $40.33 \%$ ). However, it might be indicated that on comparatively lower concentration of Altosid, the compound killed males in contrary, with higher concentrations.

ITTYCHERIAH, el al. (1974) found that Altosid analogues CRD9499 (10,11 epoxy methyl $3,7,11$ trimethy, 1-2, 6 dodecadienamide) reduced adult emergence of Culex tarsalis when it was used by topical application to eggs. $\mathrm{He}$ found also that the inhibition being significant at dosage of $10 \mathrm{ppm}$. Exposure of Aedes aegypti eggs for 7 days to $0.0001-1 \mathrm{ppm}$ concentrations of Altosid caused 12.7-79.2\% inhibition of hatching and $20-100 \%$ mortality of the resulting pupae (NAQUIL et al., 1976).

Laboratory experiments on the effect of Altosid were conducted on 
the first to fourth instar larvae as well as pupae of Culex univittatus. As indicated from larval mortality and inhibition of the adult emergence (Table 3,4), high mortality in the first and second larval instars of Culex univittatus. were obtained by using Altosid. The third and fourth instars were less sensitive. Hence, it might be indicated that Altosid might induce larvicidal effect on the early instars, whereas on the late instar, it might act as inhibitor of adult emergence. These results agree with those obtained by $B E T$ RAS and SIVERLY 1971) on Culex pipiens pallens, ITTYCHERIAH et al. (1974) on Culex tarsalis and (FARGHAL 1979) on Culex pipiens molestus.

\section{REFERENCES}

Anonymous (1972): Altosid TM (Fomerly ZR. 515). Zoecon Technical Bulletin, Zoecon corporation, 975 California Avenue, Palo Alto, Calif. 94304 415/327-2160: pp.2.

Betras, S. and Siverly, R.E. (1971): Preliminary investigation of the effect of three hormonomimetic compounds on larvae of Culex pipiens pipiens. Proceedings of the Indiana Academa of Science (1971) 81, 172 (C.F. Review of Applied Entomology Ser. B., Medical 1974, 62: 2156). Cumming, J.E. and Mackague, B. (1973): Preliminary studies of effect of Juvenile hormone analogues on adult emergence of black flies (Diptera:

Simulidae). Can Ent. 105: 509-11.

Ectwards, J.P. (1973): The effects of a Juvenile hormone analogue on laboratory colonies of pharaok's ant, Monomorium pharaonis (L.) (Hymenoptera, Formicidae). Bull. Ent. Res. 65: 75-80.

Farghal, A.I.A. (1979): Recent trends in culicine mosquitoes control Ph.D. thesis. Dept. of plant prot. Fac. Agri, Assiut University. Ittycheriah, P.I. Quarishi, M.S. and Marks, E.P. (1974): Effects of ecdysones, JH analogues and 6-ox-Octanoic acid on the development of the mosquito Culex trasalis. Candian Entomologist 106 (1): 79-85.

Naqui, S.N.H.; Rashid, S. and Ashrafi, S.H. (1976): Effect of Altosid (JHAZRSIS) on Aedes aegypti (PCSIR Strain) Zeitschrift fur Angewandt Entomologie 80 (3) 316-324. (C.F.Review of applied Entomology ser. B. Medical, 1976, 64: 2816).

Pree, D.J. (1974): Effects of insect developmental inhibitors on the apple maggot Rhagoletes pomonella (Diptera, Trypetidae). Can Ent. 106: 1019-2A.

Reid, B.L. Apple A.G. Demark J.J. and Benneti G.W. (1992): Oral toxicity, Formulation effects, and Field Performance of Flufenoxuron against the 


\section{ALTOSID, DEVELOPMENTAL STAGES OF CULEX}

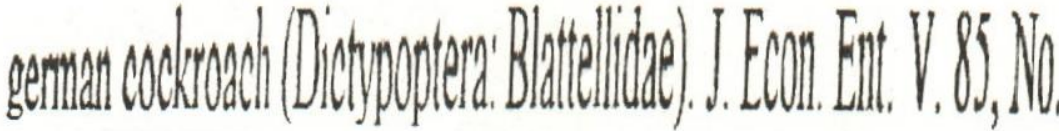

4, pp. 1194-1199.

Retnakaran, A. (1973): Ovicidal effects in the white pine weevile, Pissodes strobi (Coleoptera: Curculionidae), of a synthetic analogue of JH. Can. Ent. 105: 591-594.

Retnakaran, A. (1974): Induction of sexual maturity in the white pine weevil, Pissodes strobi (Coleoptera: curculionidae), by some analogues of Juvenile hormone. Can Ent. 106: 831-834.

Shafi, S.S.; Naqvi, N.H. and Zia N. (1987): Effects of difluben-Zuron and penfluron (IGRs) on the morphologog of Musca domestica and Blattella germanica. Pak. J. Zool. 19: 85-90.

Wadlegh, R.W. P., P.G Koehler and R.S. Patterson (1991): Age-specific reduction in German cockroach (Blattoidea: Blattellidae) populations exposed to diflubenzuron J. Entomol. Sci. 26: 244-251.

Table 1: Effect of Altosid on hatching rate of Culex univittatus eggs.

\begin{tabular}{|l|c|c|c|c|}
\hline \multirow{2}{*}{$\begin{array}{c}\text { Concentration } \\
\text { ppm }\end{array}$} & \multicolumn{3}{|c|}{ \% Hatching } & Mean \\
\cline { 2 - 5 } & Replicate 1 & Replicate 2 & Replicate 3 & \\
\hline 0.0137 & 100 & 100 & 100 & 100 \\
0.0238 & 96 & 90.23 & 96 & 94.07 \\
0.0495 & 99 & 94.51 & 98 & 97.17 \\
0.1273 & 82.30 & 72.80 & 70.30 & 75.13 \\
0.2645 & 51.40 & 53.14 & 50.77 & 51.77 \\
0.4814 & 48.43 & 54.50 & 52.30 & 51.74 \\
1.1276 & 51.33 & 48.11 & 52.33 & 50.59 \\
Control & 100 & 100 & 100 & 100 \\
\hline
\end{tabular}

Table (2): Effect of Altosid on some biological properties of Culex univittatus.

\begin{tabular}{|l|c|c|c|c|c|c|}
\hline \multicolumn{1}{|c|}{ Criteria } & \multicolumn{6}{|c|}{ Concentratious ppm } \\
\cline { 2 - 7 } & $\mathbf{0 . 0 4 9 5}$ & $\mathbf{0 . 1 2 7 3}$ & $\mathbf{0 . 2 6 4 5}$ & $\mathbf{0 . 4 8 1 4}$ & $\mathbf{1 . 1 2 7 6}$ & Control \\
\hline Larval monality & $\delta$ & 16 & 20 & 20 & 20 & 10 \\
Larval periodsidays & 7.83 & 8.5 & 8.23 & 8.41 & 8.39 & 7.92 \\
Pupal periodsidays & 3.06 & 3.58 & 3.44 & 3.10 & 3.06 & 2.81 \\
Pupal mortality & 10.21 & 10.50 & 11.93 & 11.30 & 14.62 & 9.32 \\
Femaie ratio & 42.18 & 76.83 & 68.31 & 48.12 & 40.33 & 46.14 \\
\hline
\end{tabular}




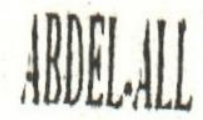

Table (3): Effect of Altosid on different larval instar of Culex univittatus.

\begin{tabular}{|l|c|c|c|}
\hline \multicolumn{1}{|c|}{ Instars* } & $\begin{array}{c}\text { Concentration of } \\
\text { Altosid (ppm) }\end{array}$ & Larval mortality & \% adult inhibition \\
\hline \multirow{3}{*}{ First } & 0.0137 & 75.8 & 4.81 \\
& 0.0238 & 72.6 & 5.77 \\
& 0.0495 & 87.3 & 8.34 \\
\hline \multirow{3}{*}{ Second } & 0.0137 & 16.0 & 9.34 \\
& 0.0238 & 25.8 & 26.71 \\
Third & 0.0495 & 51.3 & 40.5 \\
& 0.0137 & 7.81 & 13.61 \\
& 0.0238 & 16.73 & 43.72 \\
Fourth & 0.0495 & 18.21 & 56.81 \\
\hline & 0.0137 & 3.81 & 52.80 \\
& 0.0238 & 7.36 & 87.32 \\
\hline
\end{tabular}

* Control in all instar larvae 0.00

Table (4): Effect of Altosid on the Culex univittatus pupae.

\begin{tabular}{|l|c|c|c|c|}
\hline \multirow{2}{*}{$\begin{array}{c}\text { Concentrations } \\
\text { ppm }\end{array}$} & \multicolumn{3}{|c|}{ \% Adult Inhibition } & Mean \\
\cline { 2 - 5 } & Replicate 1 & Replicate 2 & Replicate 3 & \\
\hline 0.0137 & 5.42 & 5.91 & 6.24 & 5.85 \\
0.0238 & 16.21 & 17.30 & 14.20 & 15.90 \\
0.0495 & 13.08 & 18.91 & 17.22 & 16.40 \\
Control & 3.77 & 4.11 & 3.05 & 3.64 \\
\hline
\end{tabular}

